\title{
Abyección del deseo en la poesía de Ana María Martínez Sagi
}

\author{
Marta GÓMEZ GARRIDO \\ Universidad Complutense de Madrid \\ m.gomezgarrido@gmail.com
}

\begin{abstract}
RESUMEN
En el presente artículo aplicamos la teoría de la abyección enunciada por Julia Kristeva en el libro Poderes de la perversión (1988) a la obra poética de la autora Ana María Martínez Sagi (1907-2000), en especial, a su poemario Inquietud (1932). La llegada de las vanguardias y del psicoanálisis a España en el primer tercio del siglo XX, permite analizar la presencia de un determinado aspecto de la identidad autorial propia de la modernidad estética. Realizamos un recorrido por las teorías psicoanalíticas de Sigmund Freud, Ernst Kris y Julia Kristeva para entender la relación entre el arte y el psicoanálisis, tomando esta disciplina como herramienta de análisis textual efectiva por su estudio del ser humano. El análisis de esta presencia en su poesía es interesante sobre todo por dos motivos: porque entendemos mejor la obra de la poeta, poco estudiada a pesar de su interesante currículum, y porque podemos analizar la influencia de lo reprimido en su obra artística y, así, entender mejor su mecanismo de escritura.
\end{abstract}

Palabras clave: abyección, Ana María Martínez Sagi, poesía, deseo.

\begin{abstract}
In this article the Theory of Abjection presented by Julia Kristeva in her book 'Powers of Horror' (1988) is applied to the poetic works of Ana María Martinez Sagi (1907-2000), particularly to her collection of poems 'Inquietud' (1932). The arrival of the avant-garde and psychoanalysis to Spain in the first third of the 20th century allows analysing the presence of a specific aspect of the authorial identity which is common in the aesthetic modernity. We go through the psychoanalitical theories by Sigmund Freud, Ernst Kris and Julia Kristeva in order to understand the connection between art and psychoanalysis, taking this discipline as an effective tool for textual analysis because of its study of the humang being. The analysis of this presence in her poetry is interesting for two reasons above all: because we understand better the poet's works, yet poorly studied despite her interesting résumé, and because we can analyse the influence of the restraint in her artistic work, and thus, better understand her writing mechanism.
\end{abstract}

Keywords: abjection, Ana María Martínez Sagi, poetry, desire. 
A principios del siglo $\mathrm{XX}$ aparece una nueva comprensión del ser humano a raíz de las publicaciones de los trabajos de Sigmund Freud ${ }^{1}$. El pensamiento del padre del psicoanálisis marcó profundamente dicho siglo debido al escándalo que provocó su intento de elucidar racionalmente el deseo sexual, si bien, según defiende el psicoanalista Patrick Landman, amplió la conciencia que el ser humano tenía sobre sí mismo $^{2}$. De las teorías del psicoanálisis que enunció Freud nos interesan especialmente dos aspectos para conseguir entender el conflicto que surge al tratar el deseo en la poesía de Ana María Martínez Sagi: por un lado las teorías sobre la ambigüedad sexual existente en el ser humano, con las que rompe la dicotomía rígida del binomio hombre/mujer y, por otro, el poder de lo inconsciente y lo preconsciente.

En su obra Ensayos sobre la vida sexual y la teoría de la neurosis, Freud señala que "los neuróticos son aquellos hombres que, poseyendo una organización desfavorable, llevan a cabo, bajo el influjo de las exigencias culturales, una inhibición aparente, y en el fondo fracasada, de sus instintos"3, es decir, aquellos que intentan esconder sin éxito sus tendencias naturales por no ser aceptadas por su entorno social. En el sentido psicoanalítico, el exclusivo interés sexual del hombre por la mujer es una cuestión que requiere una explicación, ya que no es algo que pueda explicarse únicamente por sí mismo ni por la base de la atracción química ${ }^{4}$. El psicólogo añade también que "una de las más evidentes injusticias sociales es la de que el standard cultural exija de todas las personas la misma conducta sexual, que, fácil de observar para aquellas cuya constitución se lo permite, impone a otros los más graves sacrificios psíquicos" ${ }^{5}$. Estos sacrificios psíquicos a los que alude Freud están relacionados con la presión que ejercen los pensamientos y tendencias que el ser humano intenta ocultar. Para la investigadora Cristina Pérez Arias, el psicoanálisis, mejor que ninguna otra teoría del conocimiento, mostró cómo lo pulsional y lo simbólico actuaban sobre el Yo, presionándolo, del mismo modo que demostró que el inconsciente alteraba la consciencia imposibilitándola para realizar libremente sus tareas racionales ${ }^{6}$.

La feminista Julia Kristeva dio un paso más en las teorías enunciadas por Freud y en su obra Poderes de la perversión teoriza más en profundidad sobre aquellos elementos que conforman la identidad del Yo pero que han de reprimirse para entrar

${ }^{1}$ En 1893 Freud publica Estudios sobre la histeria, en 1900 La interpretación de los sueños y en 1905 Tres ensayos sobre la teoría de la sexualidad.

${ }^{2}$ P. Landman (1999), p. 9.

${ }^{3}$ S. Freud (1979a), p. 30.

${ }^{4}$ S. Freud (1920), p. 56.

${ }^{5}$ S. Freud (1979a), p. 31.

${ }^{6}$ C. Pérez Arias (2004), p. 2. 
en contacto con la sociedad. A lo que se reprime lo llama "abyección", provocada por la cultura dominante:

Hay en la abyección una de esas violentas y oscuras rebeliones del ser contra aquello que lo amenaza y que le parece venir de un afuera o de un adentro exorbitante, arrojado al lado de lo posible y lo tolerable, de lo pensable. Allí está, muy cerca, pero inasimilable. Eso solicita, inquieta, fascina el deseo que sin embargo no se deja seducir. Asustado, se aparta. Repugnado, rechaza, un absoluto lo protege del oprobio, está orgulloso de ello y lo mantiene. Y no obstante, al mismo tiempo, este arrebato, este espasmo, este salto es atraído hacia otra parte tan tentadora como condenada. Incansablemente, como un boomerang indomable, un polo de atracción y de repulsión coloca a aquel que está habitado por él literalmente fuera de sí .

Así, la abyección se plantea como un elemento propio, que tienta y que repugna a la vez al sujeto, lo que más adelante podremos comprobar de primera mano en los textos de la poeta. Kristeva señala además que la modernidad aprendió a reprimir, esquivar y maquillar lo abyecto ${ }^{8}$, por lo que para buscar la huella de estas emociones en los textos poéticos, habrá que buscar en lo esquivo y ambiguo.

La investigadora Elizabeth Wright apunta en la misma dirección que Kristeva al afirmar que "los instintos del Yo, preocupados por la autopreservación y la necesidad de relacionarse con otros, están en conflicto con los instintos sexuales como centro dinámico de las energías del inconsciente" . La necesaria socialización con los demás pone a los individuos que se salen fuera de la media social en una encrucijada con sus propios deseos.

La presencia de todas estas ideas que han pervivido hasta nuestros días afectó a aquellos que de forma directa o indirecta entraron en contacto con ellas. Los investigadores Antonio Sánchez-Barranco y Reyes Vallejo analizan en "Ortega y Gasset, la psicología y el psicoanálisis" (2005) la llegada del psicoanálisis a España, que se produjo principalmente de la mano de Ortega y Gasset. Fue el filósofo el responsable de pedir a José Ruiz-Castillo, editor de Biblioteca Nueva, que tradujese al castellano las obras completas de Freud, llegando a prologar en 1922 el primero de sus volúmenes, en el que afirma: "No hay duda de que algunas de estas invenciones como la represión- quedarán afincadas en la ciencia. Otras parecen un poco excesivas y, sobre todo, un bastante caprichosas"10. El filósofo español se muestra interesado por las aportaciones de Freud, especialmente por innovaciones como la repre-

${ }^{7}$ J. Kristeva (1988), p. 7.

${ }^{8}$ J. Kristeva (1988), p. 40.

${ }^{9}$ E. Wright (1985), p. 37.

${ }^{10}$ S. Freud (1922), p. 301-303. 
sión, pero no termina de comulgar con la importancia que le da el médico vienés a la sexualidad en su obra.

Francisco Vázquez y Andrés Moreno afirman en Sexo y razón: una genealogía de la moral sexual en España (siglos XVI-XX) que en el curso del primer tercio del siglo XX "cristaliza un modelo de coordinación entre médicos $-\mathrm{o}$ agentes apoyados en un saber médico-, padres y maestros, que se traduce en diversas formas de realizar la capacitación sexopedagógica" 11 .

La educación sexual, por lo tanto, estuvo controlada por los médicos en aquella época, que discriminaban lo 'patológico' de lo 'natural'. La República se negó a introducir la educación sexual en las Escuelas Normales y en los centros escolares, a pesar de ello, el debate no se establecía a favor o en contra de proporcionar una educación sexual, sino acerca de las características que ésta debía poseer ${ }^{12}$. Por ello, la derecha católica contemplaba con recelo una pedagogía sexual implantada por un Estado laico.

En aquellos años, entre los médicos dominaba una tendencia higienista de la sexualidad, caracterizada por los valores cristianos y el ascetismo. Nuria CapdevilaArgüelles señala en Autoras olvidadas que la poeta Lucía Sánchez Saornil criticó duramente en sus artículos "las nuevas teorías sobre diferenciación sexual propugnadas por Gregorio Marañón y los higienistas sexuales"13. Incluso señala que el afamado médico examinó a Ana María Martínez Sagi a petición de sus padres por sus "rarezas deportivas e intelectuales" y concluyó que la poeta estaba en un estado intersexual y diagnosticó "la deformidad de los ovarios y aparato genital de la joven Sagi" $"$.

El propio Gregorio Marañón fue el único médico español importante que conoció personalmente a Freud. En su teoría, Marañón defendió que cada ser humano estaba dotado con características de ambos sexos que se hacían patentes en ciertos momentos de su vida, a lo que él denominó estados intersexuales. Sin embargo, si en un individuo se mostraban claramente y de forma constante características del sexo opuesto, el médico lo consideraba una patología llamada intersexualidad crítica ${ }^{15}$.

Por ello, podemos deducir que tanto Mulder como Martínez Sagi conocían el contenido, o al menos parte de él, de las teorías del médico vienés. Ahora que sabemos que estas teorías influyeron de forma directa en la época, la cuestión es discernir en qué manera esas pulsiones se podrían haber reflejado en los textos de la autora. Los filósofos y psicólogos que teorizaron sobre el psicoanálisis coinciden en

${ }^{11}$ F. Vázquez y A. Moreno (1997), p. 151.

${ }^{12}$ F. Vázquez y A. Moreno (1997), p. 153.

${ }^{13}$ N. Capdevila-Argüelles (2008), p. 168.

${ }^{14}$ N. Capdevila-Argüelles (2008), p. 169

${ }^{15}$ G. Marañón (1930), pp. 69 y 135. 
recalcar la importancia del inconsciente en los procesos de creación, si bien no todos creen que esta influencia afecte de la misma manera a la labor creativa.

Para Freud la literatura y el psicoanálisis eran líneas de pensamiento separadas pero con puntos de intersección. Para el psicoanalista Carlos Rey el punto en común entre ambas disciplinas se encuentra en el desvelamiento de los enigmas de la condición humana ${ }^{16}$. Así, el psicoanálisis nos informa del proceso de creación, de hecho, en su discurso 75, denominado El interés del psicoanálisis para la estética, Freud asegura que "las fuerzas impulsoras del arte son aquellos mismos conflictos que conducen a otros individuos a la neurosis y han movido a la sociedad a la creación de sus instituciones" ${ }^{\text {"17 }}$. El padre del psicoanálisis señala que las fuerzas destinadas hacia el trabajo cultural provienen de la represión de los elementos de excitación sexual, que no están destinados a la satisfacción genital, sino a procurar placer por otros caminos, desviados de su finalidad primariamente sexual. Sobre este material, de origen sexual pero reprimido, actúa el mecanismo de la "sublimación", mediante el cual el artista transforma en cultura, en material aceptable socialmente, aquello que intenta reprimir y que es socialmente inaceptable ${ }^{18}$. La esencia de la represión consiste simplemente en desechar algo, y en mantenerlo alejado de la conciencia $^{19}$.

El psicoanalista austriaco-norteamericano Ernst Kris fue aún más claro al teorizar sobre la relación existente entre los procesos mentales y la capacidad artística. Ernst Kris llegó a establecer que el nombre técnico de las musas era preconsciente aquello que es capaz de volverse consciente fácilmente y en situaciones usualesdado que "el que habla no es el sujeto, sino una voz que sale de él. Lo que dicha voz, que surge de él, proclama, le era desconocido antes del nacimiento del estado de inspiración" ${ }^{20}$ dado que nace de su interior, de aquello que él mismo se intenta negar. En esta teoría existe un cambio importante con respecto a lo enunciado por Freud en un principio: para Ernst Kris es la capacidad manipuladora del Yo la que hace que aquello que no está del todo asumido por el individuo se muestre en sus obras artísticas, mientras que para Freud son las operaciones subversivas del Ello las que toman las riendas en la operación creativa. Elizabeth Wright analiza esta diferencia en su ensayo Psicoanálisis y critica cultural donde concreta que Kris "mantiene la analogía entre arte y sueño pero ésta ya no descansa sobre la idea de un deseo inconsciente sino que depende del modo en que las operaciones preconscientes del Yo modifican los deseos inconscientes" ${ }^{21}$, es decir, que para Ernst Kris

${ }^{16}$ C. Rey (2009), p. 146.

${ }^{17}$ S. Freud (2003), p. 1865.

${ }^{18}$ S. Freud (1979b), p. 168.

${ }^{19}$ S. Freud (1953), p. 147.

${ }^{20}$ E. Kris (1964), p. 125.

${ }^{21}$ E. Wright (1953), p. 56. 
el artista sí es consciente de aquello que se intenta reprimir aunque intente apartarlo por no estar cómodo con ello.

La relación entre ambos elementos fue tan evidente en la época de la vanguardia, a la que perteneció la autora estudiada, que Pío Baroja, nada relacionado en principio con el psicoanálisis, también llegó a afirmar que el arte actual nace del subconsciente, y concreta más: "el arte antiguo hablaba del entendimiento; el moderno, más carnal, habla sólo a la sensualidad y a la subconsciencia" 22 .

Por lo tanto, el inconsciente (y el preconsciente) se ha llegado a concebir como una de las fuentes de las que mana lo artístico, pero la relación es más compleja y se retroalimenta. Aquello que el artista pretende ocultar, lo "abyecto" como lo llama Kristeva, influye en su obra pero, a la vez, el hecho de expresar esa abyección en una obra artística ayuda también a liberarla. A este respecto Kris apunta que el arte "libera las tensiones inconscientes y purga el alma",23, además señala esta conclusión como el denominador común entre las teorías de Aristóteles y Freud sobre la actividad creadora.

La investigadora Elizabeth Wright apunta que "los mismos mecanismos que según Freud determinan la conducta normal y anormal entran significativamente en juego cuando se encara cualquier tipo de actividad estética". El profesor Perry Meisel parece coincidir en esta misma relación entre la conducta y la estética e incluso va más allá al considerar que la principal especulación literaria de Freud reside en la idea de que los propios mecanismos de los agentes mentales son los mecanismos del lenguaje, y no sólo de la actividad creadora ${ }^{24}$. Podemos suponer que aquellas personas que finalmente realizan una conducta anormal, o fuera de lo que se puede considerar una mayoría, también plasmarán esa forma de actuar o esas preferencias en sus actividades estéticas e incluso en su lenguaje, ya que los mecanismos que el sujeto tiene que superar en ambos casos son los mismos y se puede suponer que la consecuencia también será la misma. Kristeva también recalca en sus ensayos la importancia del arte en la abyección:

Es en la literatura donde la vi finalmente realizarse, con todo su horror, con todo su poder. Si se mira de cerca, toda la literatura es probablemente una versión de ese apocalipsis que me parece arraigarse, sean cuales fueren las condiciones socio-históricas, en la frontera frágil donde las identidades no son o sólo son apenas -dobles, borrosas, heterogéneas, animales, metamorfoseadas, alteradas, abyectas $^{25}$.

${ }^{22}$ P. Baroja (1980), p. 851. Pío Baroja lo llama subconsciente, pero por el contexto probablemente se refería al inconsciente.

${ }^{23}$ E. Kris (1964), p. 62.

${ }^{24}$ P. Meisel (1981), p. 2.

${ }^{25}$ J. Kristeva (1988), p. 277. 
Por ello, para la autora, la literatura es la codificación última de nuestras crisis. La investigadora Diana Paris concluye en su obra Julia Kristeva y la gramática de la subjetividad que "la producción artística constituye otro modo de nombrar el sufrimiento, de complacerse en la depresión, de sobrepasar el duelo inacabado"26. Esta visión es especialmente relevante para el análisis que nos proponemos hacer, ya que relaciona de forma directa el sufrimiento con la necesidad de expresar aquello que nos hace daño, aunque sea, como dijimos anteriormente, a través de las verdades veladas y el maquillaje.

El lenguaje poético parece ser el más adecuado para esta especie de catarsis, ya que designa de forma diferente a la lengua usada para la comunicación ordinaria, "es otra lengua que incorpora la contradicción, la vida y la muerte, el ser y el no ser, lo bueno y lo malo que pueden existir simultáneamente en un texto" ${ }^{\text {27 }}$. Ahora vamos a comprobar la presencia de esta catarsis en los textos poéticos de la autora catalana Ana María Martínez Sagi, pero primero realizaremos un somero repaso sobre su vida.

Ana María Martínez Sagi nació en Barcelona el 19 de febrero de 1907, en el seno de una familia perteneciente a la burguesía más acomodada e industrial de la Ciudad Condal. Destacó tanto en el deporte ${ }^{28}$ como en las letras, con un curioso y variado perfil que atrajo la atención de los críticos de la época. Comenzó a escribir poemas con apenas veintidós años, con inquietudes entre románticas y modernistas y, como señala la doctora Dolores Romero en el artículo "Las poetas del 27: Identidad femenina en tiempos de guerra" (2010), ése fue su estilo a lo largo de toda su producción. En 1929 publicó Caminos, su primera obra poética, un libro en el que según el escritor Juan Manuel de Prada "se aprecian las resonancias de las poetisas sudamericanas por entonces en boga" 29 . Como recuerda Prada en su artículo, la obra fue recibida con alabanzas unánimes por autoridades literarias de la talla de Antonio Machado o Rafael Cansinos-Asséns. En 1932 publicó Inquietud, "donde ya apuesta por ese despojamiento reflexivo y ese simbolismo telúrico que caracterizarán su mejor poesía" ${ }^{30}$. En 1936 ejerció como corresponsal de guerra en el Frente de Aragón aunque más tarde se exilió a Francia desde donde trabajó en la resistencia. En

${ }^{26}$ D. Paris (2003), p. 43.

${ }^{27}$ D. Paris (2003), p. 82.

${ }^{28}$ Llegó a disputar la final del Campeonato de España de tenis y batió varias marcas nacionales de lanzamiento de jabalina. Además, la autora fundó el pionero "Club Femeni i d'Esports" y desempeñó durante un tiempo un cargo de responsabilidad en la Junta del F. C. Barcelona, convirtiéndose en la primera mujer directiva de un equipo de fútbol (Prada, 1998: 148).

${ }^{29}$ J. M. de Prada (1998), p. 147.

${ }^{30}$ J. M. de Prada (1998), p. 148. 
1969 regresó a España y publicó Laberinto de presencias $^{31}$, una obra recopilatoria con la que cerró la publicación de sus creaciones.

Para la presente comunicación nos centraremos especialmente en sus poemarios a partir de 1932, ya que es la fecha en la que tendrá lugar su relación con la también escritora Elisabeth Mulder, que será la causante de la presencia de la abyección en la obra de la autora catalana. Fue Juan Manuel de Prada en la obra Las esquinas del aire (2000), basada en la vida de la poeta, el que investigó su rastro hasta dar con el secreto, guardado hasta entonces, casi como su obra, que había caído en el olvido. Rubén Castillo Gallego resume el descubrimiento de Prada de la siguiente manera:

En síntesis, se puede decir que nuestros investigadores descubren que hubo un secreto candente que laceró las entrañas emocionales de Ana María, y que el lastre doloroso generado por la separación enturbió sus horas desde 1932 (en que se produjo la ruptura). [...] Es mucho tiempo, sin duda, para atreverse a definir esta relación como meramente episódica o genita $l^{32}$.

Al principio los investigadores sólo tienen pistas y pequeñas conjeturas sobre la relación existente entre ambas mujeres: "La hipótesis era plausible, sugestiva, incalculablemente hermosa, pero le faltaba el condimento de las pruebas" ${ }^{33}$. Será más tarde, cuando encuentren a la poeta en su vejez, cuando confirmen la relación que "fue un espejismo de plenitud que sólo duró unas semanas"34.

A la hora de analizar la presencia de la abyección en la poesía de Ana María Martínez Sagi encontramos un término recurrente para referirse a esa sensación de atracción y repugnancia: la inquietud. Llegando incluso a titular a uno de sus poemarios con dicho nombre. El deseo en sus poemas se vive como un arma de doble filo que lleva a experiencias "divinas" pero a la vez quema y duele. El lenguaje relacionado con el deseo no suele ser concreto, sino ambiguo, como señala Elizabeth Wright "el lenguaje del deseo es velado, no se muestra abiertamente", aún más en aquellos casos en los que se desea algo prohibido ya que "las energías del deseo se dirigen fuera de la percepción consciente y se adhieren a ideas e imágenes particulares, que representan deseos inconscientes" ${ }^{\$ 3}$. En el contexto de sus poemas, la inquietud refleja un deseo imparable y asfixiante:

${ }^{31}$ En esta obra incluye Canciones entre la isla (1936), País de ausencia (1940), Los motivos del mar (1955), Visiones y sortilegios (1960), Jalones entre la niebla (1967), Amor perdido (1968).

${ }^{32}$ R. Castillo Gallego (2006), p. 117.

${ }_{33}^{33}$ J. M. de Prada (2000), p. 250.

${ }^{34}$ J. M. de Prada (2000), p. 521

${ }^{35}$ E. Wright (1985), p. 1. 
Desgárrame la carne fieramente ¡con el zarpazo violento de tus garras!

pide Martínez Sagi en "Canto a la inquietud"36, en esta misma poesía la inquietud se presenta como "misteriosa y dominante" así como "infernal", pero sin ella, el yo lírico no sabe vivir: “¡Inquietud no me abandones! / ¡Tengo miedo de vivir si tú me faltas!" y finaliza el poema con la siguiente estrofa:

¡Únete a mí! Me entrego sin reservas

como una novia sumisa y confiada.

Desgárrame la carne fiéramente

¡con el zarpazo violento de tus garras!

En el poema "Tortura" ${ }^{37}$ Martínez Sagi habla de un pensamiento que se le clava en la carne y que es "abismo terrible, negrura" y que la arrastra hacia el descontrol:

¡Oh, Dios; cómo duele a mi alma

su zarpazo infame,

y se hunde la frente que oculta

la huella humillante!

Y no sé... Y no sé... Tengo miedo

de no poder arrancarle,

de que me arrastre en su vértigo

de que me venza y me aplaste,

iy me convierta en esclava

que no puede liberarse!

¡Pensamiento! ¡Pensamiento!

Huracán que levantas tempestades.

Llama ardiente y pavorosa que me quemas.

Marea alta que me llevas y me traes.

¿No te dan compasión mis ojos limpios?

En la poesía que la poeta le dedica a Elisabeth Mulder $^{38}$ la califica de "Abismo de inquietud, sima profunda", con lo que toda ella se convierte en sí misma en ese abismo que lleva a la perdición.

En el poema "Mis cantos" 39 perteneciente al mismo poemario y que podría considerarse casi una poética de la autora, menciona también esta inquietud: "Cancio-

${ }^{36}$ A. M. Martínez Sagi (1932), p. 15.

${ }^{37}$ A. M. Martínez Sagi (1932), p. 43.

${ }^{38}$ A. M. Martínez Sagi (1932), p. 59.

${ }^{39}$ A. M. Martínez Sagi (1932), p. 67. 
nes de dudas, de celos, / de inquietudes y alegrías, / canciones de altos anhelos / y ocultas melancolías".

En "Confesión" " vuelve a estar presente la inquietud con el mismo papel dentro del juego del deseo:

La inquietud es entonces

mi sola compañera,

y una fuerza misteriosa me tortura,

me rinde, me aniquila, me doblega,

y es cuando sufro, y grito, y lloro, y rujo,

y soy salvaje lo mismo que una fiera.

En estos días sombríos

todas las horas son negras.

A pesar de rebelarse constantemente contra la sensación que le provoca la inquietud, en muchas de sus composiciones se rinde ante ella, como podemos observar en el poema "Canto al dolor" $"$, en el que escribe:

Mas no importa. Te quiero, sembrador, embrujado, que esparces por mis sendas tus semillas inquietas.

¡No nací para ser un regato encalmado, ni quiero que mis horas sean mansas y quietas!

Deseo sentir siempre el zarpazo sangriento que abre en mi carne blanca un profundo desgarro: por tus heridas, brota mi claro sentimiento, por ti, Dolor, me olvido que estoy hecha de barro.

En el poemario Laberinto de presencias (1969) se sigue notando la huella de ese deseo que arde y quema, y que, por lo tanto, genera tanto placer como dolor. En el poema "El beso" "42 la poeta se pregunta:

¿Qué puñales de luna qué dardos acerados abren mi cuerpo frío y me penetran ciegos?

¿A qué vértigos puros a qué cuencas recónditas

a qué cielos efímeros a qué vastos incendios

hechizada y demente

me conduce tu beso?

${ }^{40}$ A. M. Martínez Sagi (1932), p. 89.

${ }^{41}$ A. M. Martínez Sagi (1932), p. 115.

${ }^{42}$ A. M. Martínez Sagi (1969), p. 125. 
La noche en la poesía de Martínez Sagi está relacionada con el deseo reprimido, es el escenario donde el deseo se puede desarrollar. Cuando Kristeva habla de la abyección, afirma que ésta "conserva aquella noche donde se pierde el contorno de la cosa significada, y donde sólo actúa el afecto imponderable"43. El poema "El deseo"44 se desarrolla durante la noche y supone un resumen claro de la presencia de la abyección en su poesía, como podemos comprobar en este fragmento:

Gritos broncos derriban
murallas de silencio.
Sofocante me absorbe,
la boca que no tengo.
Mordaza de mi mutismo.
Pantera de mi desierto.
Hoguera de mi penumbra.
Abismo de mi tormento.
En un rojo
revuelo
de combates
sin freno
abierta
desmembrada
me consumo y me pierdo.
En la noche demente
resucitada muero:
con la boca quemada
con los flancos ardiendo.

En esta muestra de poemas de Ana María Martínez Sagi hemos podido comprobar cómo se confirman teorías psicoanalíticas sobre la escritura y el inconsciente, ya que la poeta ha dejado en sus poemas la huella de su deseo, vivido de una manera abyecta en el sentido que Julia Kristeva la definió: a través de la atracción y la repulsión unidas en un solo sentimiento.

\section{OBRAS CITADAS}

\section{FUENTES PRIMARIAS}

MARTíNEZ SAGI, Ana María: Caminos, Barcelona, Industr. Graf. Guinart, 1929. : Inquietud, Barcelona, 1932.

${ }^{43}$ J. Kristeva (1988), p. 18.

${ }^{44}$ A. M. Martínez Sagi (1969), p. 173. 


\section{: Laberinto de presencias, León, 1969.}

\section{FUENTES SECUNDARIAS}

BAROJA, Pío: Obras completas, Tomo VIII, Madrid, Biblioteca Nueva, 1980.

CAPDEVILA-ARGÜELleS, Nuria: Autoras inciertas. Voces olvidadas de nuestro feminismo, Madrid, Horas y HORAS, 2009.

CASTillo Gallego, Rubén: La voz de los otros, Murcia, Universidad de Murcia, 2006.

Freud, Sigmund: Obras completas de Sigmund Freud. V. 1, Psicopatología de la vida cotidiana, con prólogo de José Ortega y Gasset, Madrid, Biblioteca Nueva, 1922.

: The standard edition of the complete psychological works. Vol. IX y XIV, Londres, The Hogarth Press and the Institute of Psychoanalysis, 1953.

: Ensayos sobre la vida sexual y la teoría de la neurosis. Madrid, Alianza Editorial, 1979a.

: La moral sexual cultural y la nerviosidad moderna, IX, Buenos Aires, Amorrortu, $1979 b$.

: Obras completas. Tomo II, Ensayos XXVI al XCVII: (1905-1915[1917]), Madrid, Biblioteca Nueva, 2003.

KRIS, Ernst: Psicoanálisis del arte y del artista, Buenos Aires, Paidós, 1964.

KRISTEVA, Julia: Poderes de la perversión, Buenos Aires, Catálogos Editora en colaboración con Siglo XXI Editores, 1988.

LANDMAN, Patrick: Freud, Madrid, Ediciones Istmo, 1999.

MARAÑóN, Gregorio: La evolución de la sexualidad y los estados intersexuales. Madrid, Morata, 1930.

MEISEL, Perry: Freud: a collection of critical essays, Nueva Jersey, Prentice-Hall, 1981.

PARIS, Diana: Julia Kristeva y la gramática de la subjetividad, Madrid, Campo de ideas, 2003.

PÉREZ ARIAS, Cristina: La literatura como cura en la obra de Julia Kristeva, Madrid, Facultad de Filosofía U. Complutense de Madrid, 2004.

PRADA, Juan Manuel de: "Desolada ausencia", El Extramundi y los papeles de Iria Flavia, 14 (1998), Fundación Camilo José Cela, pp. 146-163.

- Las esquinas del aire. En busca de Ana María Martínez Sagi, Barcelona, Planeta, 2000.

REY, Carlos: "Las otras lecturas de Freud. Psicoanálisis y literatura", Revista de la Asociación Española de Neuropsiquiatría, 29 (2009), pp. 145-155

ROMERO LÓPEZ, Dolores: "Las poetas del 27: Identidad femenina en tiempos de guerra", en Memoria de la Guerra Civil en las escritoras española, Marina Mayoral y $\mathrm{M}^{\mathrm{a}}$ del Mar Mañas (coords.), Madrid, Sial Ediciones, 2010, pp. 75-109.

SÁNCHEZ-BARRANCO, Antonio y Reyes Vallejo: "Ortega y Gasset, la psicología y el psicoanálisis", Revista de la Asociación Española de Neuropsiquiatría, Vol. XXV, 95, julio/septiembre (2005), pp. 121-137.

VÁZQUEZ, Francisco y MORENO, Andrés: Sexo y razón: una genealogía de la moral sexual en España (siglos XVI-XX), Madrid, Ediciones Akal, 1999.

WRIGHT, Elizabeth: Psicoanálisis y crítica cultural, Buenos Aires, Per Abbat, 1985. 